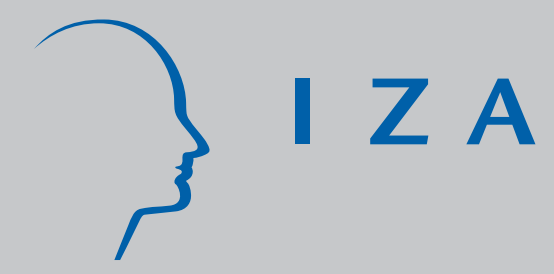

IZA DP No. 3841

Does the Growth Process Discriminate against Older Workers?

François Langot

Eva Moreno-Galbis

November 2008 


\title{
Does the Growth Process Discriminate against Older Workers?
}

\author{
François Langot \\ GAINS-TEPP, Université du Maine, \\ ERMES, Université de Paris 2, \\ Cepremap and IZA \\ Eva Moreno-Galbis \\ GAINS-TEPP, Université du Maine \\ and Cepremap
}

Discussion Paper No. 3841 November 2008

\author{
IZA \\ P.O. Box 7240 \\ 53072 Bonn \\ Germany \\ Phone: +49-228-3894-0 \\ Fax: +49-228-3894-180 \\ E-mail: iza@iza.org
}

\begin{abstract}
Any opinions expressed here are those of the author(s) and not those of IZA. Research published in this series may include views on policy, but the institute itself takes no institutional policy positions.

The Institute for the Study of Labor (IZA) in Bonn is a local and virtual international research center and a place of communication between science, politics and business. IZA is an independent nonprofit organization supported by Deutsche Post World Net. The center is associated with the University of Bonn and offers a stimulating research environment through its international network, workshops and conferences, data service, project support, research visits and doctoral program. IZA engages in (i) original and internationally competitive research in all fields of labor economics, (ii) development of policy concepts, and (iii) dissemination of research results and concepts to the interested public.
\end{abstract}

IZA Discussion Papers often represent preliminary work and are circulated to encourage discussion. Citation of such a paper should account for its provisional character. A revised version may be available directly from the author. 
IZA Discussion Paper No. 3841

November 2008

\section{ABSTRACT}

\section{Does the Growth Process Discriminate against Older Workers?}

This paper seeks to gain insights on the relationship between growth and unemployment, when considering heterogeneous agents in terms of age. We introduce life cycle features in the endogenous job destruction framework à la Mortensen and Pissarides (1998). We show that, under the assumption of homogeneous productivity among workers, firms tend to fire older workers more often than young ones, when deciding whether to update or not a technology: there is an equilibrium where the creative destruction effect dominates over the capitalization effect for old workers, whereas the capitalization effect dominates for young workers. This discrimination against older workers can be moderated when we introduce heterogeneity (in terms of productivity) among workers. We also provide empirical support for these theoretical findings using OECD panel data and numerical simulations of the model.

JEL Classification: J14, J24, J26, O33

Keywords: $\quad$ TFP growth, unemployment by age, old workers' employment rate, capitalization, creative destruction effect

Corresponding author:

Eva Moreno-Galbis

GAINS

Université du Maine

Avenue Olivier Messiean

72085 Le Mans cedex

France

E-mail: Eva.Moreno-Galbis@univ-lemans.fr

\footnotetext{
* We thank C. Quintero-Rojas for helpful discussions as well as all seminar participants at the Catholic University of Louvain, ERMES seminar of Paris II and the EALE and SED conferences 2008. Any remaining errors are ours.
} 


\section{Introduction}

The relationship between growth and unemployment has been largely analyzed in the economic literature. In his seminal work, Pissarides (1990) claims that an acceleration of growth improves the employment rate, because growth increases "freely", as in the Solow model, the expected profits and then provides incentives to open new jobs (the capitalization effect). In contrast, Aghion and Howitt (1994) argue that growth fosters a "creative destruction" process inducing more job destruction and less job creation, yielding higher unemployment rates. What effect (creative destruction vs. capitalization) prevails in the case of acceleration in the growth rate? As remarked by Mortensen and Pissarides (1998), if the cost of adopting the new more productive technology in an already existing job is higher than the cost of creating a new job, growth leads to creative destruction (more unemployment). Conversely, if the updating cost is below the creation cost, growth can lead to capitalization (less unemployment).

Even if, from a theoretical point of view, the link between growth and employment is ambiguous, empirical studies report clearer results. Using a traditional econometric approach, i.e. a panel of OECD countries, Blanchard and Wolfers (2000) or Pissarides and Vallanti (2007) show that an increase in growth pushes down unemployment. Similarly, using several measures of co-movements in the frequency domain, Tripier (2007) shows that the long-run co-movement between unemployment and productivity is strongly negative, in the US and Europe. Moreover, the simultaneous slowdown in productivity growth and the rise in the unemployment rate in OECD countries supports the view of a positive correlation between these two phenomena. The empirical evidence then suggests that the capitalization effect of growth overcomes the creative destruction effect, leading to a decrease in the long term aggregate unemployment rate. Does this mean that Aghion and Howitt (1994) were wrong when claiming that an acceleration of growth is associated with a creative destruction effect leading to a rise in unemployment rates? We believe the answer is negative as soon as we consider heterogeneous agents.

In this paper, we show that the relative magnitude of the capitalization and the creative destruction effects depends on the age of the worker. Our idea is supported by US data. Figure 1 displays the relationship between the growth rate of the HP component of the TFP (total factor productivity) and the relative employment rate of young and old workers (we will consider as young workers those having still ten years before retirement) in the US. We observe that the relative employment rate of 25-54 year old workers in the US follows exactly the same path as 
the TFP growth rate. Moreover, the structural break suffered in TFP growth in the second half of the nineties is exactly reproduced by the relative employment rate. In contrast, the relative employment rate of the US 55-64 year old workers follows an inverse path with respect to that of TFP growth, with a decreasing trend until the mid-nineties and an upward trend afterwards.
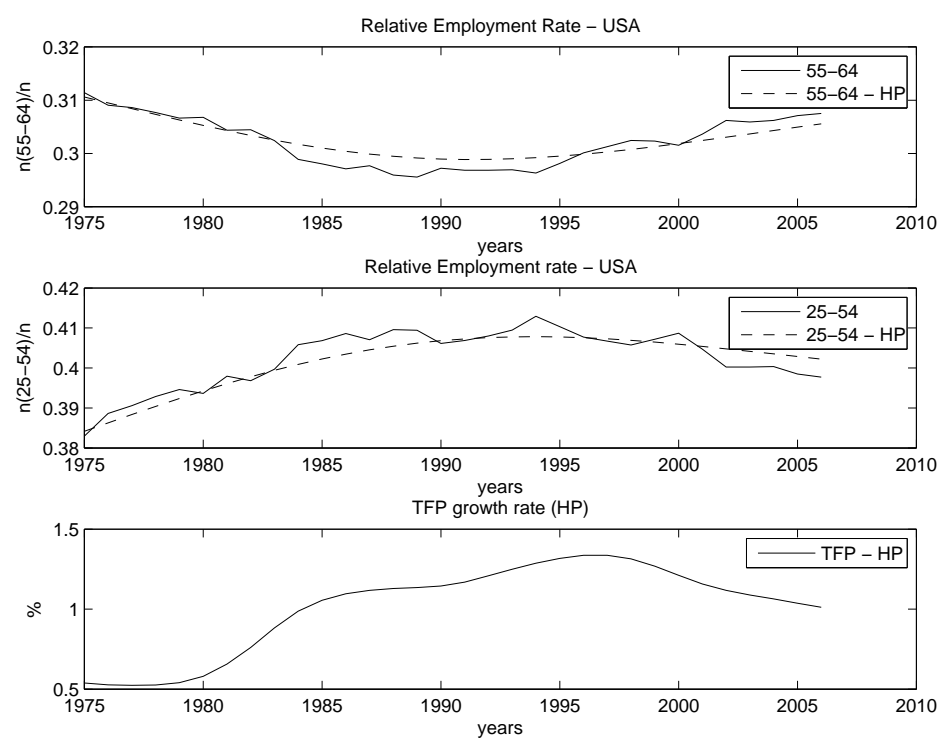

Source: Bassanini and Duval (2006).

Figure 1: Relationship between the HP component of the TFP growth and the relative employment rate of young and old workers, US 1976-2006.

The effect of growth on employment then seems to evolve along the life cycle, since it has a positive effect during the earlier period and a negative effect when approaching to retirement. Using an OECD database (see Bassanini and Duval (2006)) we propose a more formal econometric test of this assumption. Econometric estimates are shown in Table 1. The employment rate of young workers increases with the HP component of the TFP growth rate, whereas that of old workers decreases. Young employment rates display an elasticity with respect to growth equal to 0.88 whereas that of old workers equals -3.25 . In these regressions, we control for labor market institutions ${ }^{1}$, for business cycles, for the degree of product market regulation ${ }^{2}$, for the

\footnotetext{
${ }^{1}$ We choose the traditional indicators of the labor market institutions: the average replacement rate, the tax wedge, the employment protection for regular contracts, the union density and an indicator of the union coverage.

${ }^{2}$ OECD summary indicator of regulatory impediments to product market competition in seven nonmanufacturing industries.
} 
terms of trade $\operatorname{shock}{ }^{3}$, for the real interest rate $\operatorname{shock}^{4}$, for the labor demand $\operatorname{shocks}^{5}$, for time specific effects and for country specific heterogeneity. Most labor market institutions are significant and display the expected sign. More precisely, high taxes, a high replacement ratio or significant union density negatively influence the employment rate of both young and old workers (union density appears as non significant for old workers). In contrast, the effect of employment protection is negative for young workers and positive for old ones. In the regression of older workers, we also control for the heterogeneity arising from country specific Social Security rules (the implicit tax on continued activity, SS tax, and the normal retirement age). Our estimations reveal that the employment rate of old workers increases with the normal retirement age and decreases with the social security tax (see Gruber and Wise (1999) and Hairault, Langot, and Sopraseuth (2008)).

How can we relate this stylized fact to the labor demand decisions of firms? When a worker is young, the time horizon during which a firm can recoup the updating cost of renovating an existing technology is longer than for a senior. So, the optimal policy for the firm is to frequently renovate jobs occupied by young workers, whereas separation is the best choice if the job is occupied by an old worker. In this scenario, the capitalization effect can explain the positive relation between the employment rate of young workers and growth, whereas the creative destruction effect explains the low employment rate of older workers.

The effect of growth on the employment rate of heterogeneous agents has traditionally been analyzed using theoretical or empirical frameworks where the source of heterogeneity arises from the individual's skill level (see for example Berman, Bound, and Griliches (1994), Machin and Van Reenen (1998) or Moreno-Galbis and Sneessens (2007)). However, to our knowledge, there are few studies analyzing whether a given individual is equally exposed to the consequences of growth along her life-cycle ${ }^{6}$. Our paper focuses on this issue. More precisely we analyze the conditions under which the acceleration of growth fostered by the diffusion of technological progress is systematically biased against old workers. Our intuition is that the shorter horizon of older workers decreases the incentive to renovate the technology employed in their jobs.

\footnotetext{
${ }^{3}$ Logarithm of the relative price of imports weighted by the share of imports in GDP.

${ }^{4}$ Difference between the 10-year nominal government bond yield (in \%) and the annual change in the GDP deflator (in \%).

${ }^{5}$ Logarithm of the labor share in business sector GDP purged of the short-run influence of factor prices.

${ }^{6}$ For an empirical study, see Aubert, Caroli, and Roger (2006) who analyze the effects of new technologies on the French labor flows by age or the paper of Bartel and Sichermann (1993) working with US data.
} 
Table 1: Relationship between the employment rate of the young and old workers and the HP component of the TFP growth

\begin{tabular}{|c|c|c|}
\hline & Employment rate $25-54$ & Employment rate $55-64$ \\
\hline \multirow[t]{2}{*}{ HP TFP growth } & .8819461 & -3.249773 \\
\hline & {$\left[\begin{array}{ll}.1326036 & 1.631289\end{array}\right]$} & {$[-6.716418 .2168713]$} \\
\hline \multirow[t]{2}{*}{ Social Security tax } & & -14.40252 \\
\hline & & {$[-25.5945 \quad-3.210536]$} \\
\hline \multirow[t]{2}{*}{ Normal retirement age } & & 1.159734 \\
\hline & & {$\left[\begin{array}{lll}.1022486 & 2.217219\end{array}\right]$} \\
\hline \multirow[t]{2}{*}{ Average replacement rate } & -.041745 & -.4896738 \\
\hline & [-.0688739 -.0146162] & [-.6034728 -..3758748] \\
\hline \multirow[t]{2}{*}{ Tax wedge } & -.1748886 & -.4628401 \\
\hline & {$[-.2498766-.0999006]$} & [-.6806311 -.2450492] \\
\hline \multirow[t]{2}{*}{ Employment Protection } & -.3380112 & 8.698647 \\
\hline & {$[-.8093271 .1333047]$} & {$\left[\begin{array}{lll}6.734719 & 10.66258\end{array}\right]$} \\
\hline \multirow[t]{2}{*}{ Union density } & -.0321676 & -.0121176 \\
\hline & [-.0438304 -.0205048] & {$[-.0944957 .0702605]$} \\
\hline \multirow[t]{2}{*}{ Union coverage } & 8.155084 & 4.651275 \\
\hline & {$\left[\begin{array}{lll}5.930053 & 10.38011\end{array}\right]$} & {$\left[\begin{array}{lll}-2.588994 & 11.89154\end{array}\right]$} \\
\hline \multirow[t]{2}{*}{ Output gap } & .4939328 & .2705669 \\
\hline & {$[.3941441 .5937216]$} & {$[.0767911 .4643427]$} \\
\hline \multirow[t]{2}{*}{ PMR } & -.645664 & -.3097638 \\
\hline & [-1.101753 -.1895749] & {$\left[\begin{array}{lll}-1.786286 & 1.166759\end{array}\right]$} \\
\hline \multirow[t]{2}{*}{ Terms of trade shock } & 2.29217 & 54.53976 \\
\hline & {$[-2.5285717 .112911]$} & {$[31.3308277 .7487]$} \\
\hline \multirow[t]{2}{*}{ Interest rate shock } & -3.873 .271 & -.0800426 \\
\hline & {$[-8.44392 .6973773]$} & {$\left[\begin{array}{lll}-27.68861 & 27.52852\end{array}\right]$} \\
\hline \multirow[t]{2}{*}{ Labor demand shock } & -.3598445 & .1097185 \\
\hline & [-.5261844 -.1935046] & {$[-.2326163 .4520534]$} \\
\hline \multirow[t]{2}{*}{ Year } & -.3101148 & -.1870522 \\
\hline & {$[-.3975999-.2226297]$} & {$\left[\begin{array}{ll}-.4596589 & .0855544]\end{array}\right]$} \\
\hline \multirow[t]{2}{*}{ Country } & .0649241 & .4479833 \\
\hline & [.0178884 .1119598] & {$[.2338563 .6621102]$} \\
\hline \multirow[t]{2}{*}{ Constant } & 711.8376 & 367.9591 \\
\hline & [536.1758 887.4994] & [-159.6012 895.5195] \\
\hline
\end{tabular}

Cross-sectional time-series FGLS regression

Countries: BEL, FRA, ITA, GBR, SWE, DNK, USA and CAN

Period: 1982-2003

Data set Bassanini and Duval [2007]. 
We use a vintage model inspired by Mortensen and Pissarides (1998). Beyond the heterogeneity arising from the age of the vintage, life cycle features are also considered. Following here Castaneda, Diaz-Gimenez, and Rios-Rull (2003) and Ljunqvist and Sargent (2008), agents age stochastically. We assume that the population can be divided into 3 age groups: prime-age workers, old workers and retirees. A firm hiring an old worker knows that he will retire with a given probability and, similarly, a firm hiring a young worker interiorizes the fact that he will become old at a given probability. A match between the firm and the worker ensues as long as the associated surplus is positive.

We find that the acceleration in the rate of technological progress reduces the scrapping time of machines/workers (more job destruction). Besides, firms prefer, in principle, to update technologies associated with younger workers since they can smooth their investment during a longer period of time (young workers become old while occupying the same job). In the stationary equilibrium of the model, young workers' positions are situated at the technological frontier, or close to best technology, whereas old workers remain in technologically obsolete jobs (this is coherent with the empirical findings of Abowd et al. (2007), Ahituv and Zeira (2000) or Borghans and Weel (2002)). Nevertheless, this result can be moderated if we distinguish between old workers whose productivity is relatively high and those whose productivity is relatively low. In this case, even if the working horizon is short, it is more profitable for the firm to train a high productivity worker rather than to destroy the job and create a new one (this corresponds to the estimations of Behaghel and Greenan (2007) for the French economy).

Finally, the numerical simulations provided in Section 6 reveal that, for reasonable parameter values, the capitalization effect overcomes the creative destruction effect for young workers. The situation is reversed when considering the old worker population. However, a puzzle arises: we are unable to reproduce the estimated elasticities of employment with respect to growth both in the young and the old segment. Concerning the elasticity of employment of prime age workers (young segment), we perform several sensitivity analysis. On the one hand, in order to increase the sensitivity of employment with respect to growth, we reduce the value of the elasticity of the matching function with respect to unemployment as well as the value of the workers' outside option. By increasing the expected profits of the firm, we stimulate the opening of new vacancies. The probability of finding a job increases and so does the number of employees. The elasticity of employment of prime age workers with respect to growth is then largely improved by simply reducing the two previous parameters. 
The situation on the old segment is somewhat different. Because their working horizon is very short, most workers retire before an exogenous or an endogenous destruction shock can arrive. As a result, the effect of growth on the employment rate of old workers is very reduced, since growth does not have any impact on the exogenous probability of retirement, which constitutes the main factor responsible for the exits from employment in this sector.

The paper is organized as follows. The next section presents the main assumptions of the model as well as the agents' behavior. In Section 3 we describe the main characteristics of an equilibrium where the firm does not have the possibility of updating a technology. We also analyze the effects of an increase in the pace of technological progress. We systematically contrast the results obtained under the hypothesis of rigid wages with those that we would have obtained if wages were flexible. Section 4 introduces the possibility of updating a technology rather than destroying the job in a context where there are no productivity differentials within the group of old and and young workers. Section 6 presents some numerical results. Section 7 concludes.

\section{The model}

\subsection{Assumptions}

We build a matching model based on Mortensen and Pissarides (1998) where the economy is populated by a continuum of firms and workers. Each firm employs only one worker. Workers may be young or old. We will denote $X_{y}$ all variables referring to young workers and $X_{o}$ those referring to old. The exogenous probability of becoming old is represented by $\lambda_{y}$, so that workers remain young for a period equal to $1 / \lambda_{y}$. Older workers retire with probability $\lambda_{o}$, therefore they are old during $1 / \lambda_{o}$ periods (see Figure 2). In this stylized life cycle model, we assume that the risk of becoming a retiree is borne for a short duration of time. We therefore restrict then $\lambda_{o}$ and $\lambda_{y}$ such that $\lambda_{o}>\lambda_{y}$. The progression of the total population of young and old workers is respectively given by:

$$
\begin{aligned}
& \dot{P}_{y}=\lambda_{o} P_{o}-\lambda_{y} P_{y} \\
& \dot{P}_{o}=\lambda_{y} P_{y}-\lambda_{o} P_{o}
\end{aligned}
$$

where $\lambda_{o} P_{o}$ stands for the fraction of old workers retiring and so leaving the old workforce. Because the aggregate workforce is assumed to be constant, this proportion of old workers 
retiring must equal the entries into the young workforce. Similarly, $\lambda_{y} P_{y}$ represents the exits from the young segment and the entries to the old one. Normalizing $P_{y}$ to one we obtain $P_{o}=\lambda_{y} / \lambda_{o}$

At each moment of time a mass $u_{i}$ for $i=y, o$ of unemployed workers and a mass $v_{i}$ for $i=y, o$ of vacant jobs coexist on the labor market. Firms may direct their open vacancy either to a young or an old worker. Jobs and workers meet pairwise at a Poisson rate $M\left(u_{i}, v_{i}\right)$, where $M\left(u_{y}, v_{y}\right)$ stands for the matching function in the young segment and $M\left(u_{o}, v_{o}\right)$ for the matching function in the old segment. This function is assumed to be strictly increasing and concave, exhibiting constant returns to scale. Furthermore it satisfies the Inada conditions and $M\left(0, v_{i}\right)=M\left(u_{i}, 0\right)=0$. Under these assumptions and knowing that $M\left(u_{i}, v_{i}\right)$ represents the number of matches per unit of time, we can represent the probability of filling a vacancy as $q\left(\theta_{i}\right)=M\left(u_{i}, v_{i}\right) / v_{i}=M\left(\theta_{i}, 1\right) / \theta_{i}$ for $i=y, o$. Equivalently, the probability of finding a job is given by $p\left(\theta_{i}\right)=M\left(u_{i}, v_{i}\right) / u_{i}=M\left(\theta_{i}, 1\right)$ for $i=y, o$.

Assuming that young and old workers have the same productivity, firms prefer young workers because they can produce for a longer period of time. However the free entry condition ensures that firms post vacancies for both types of workers. It is always in the interest of an old worker, to search in the young labor market segment since there are more job opportunities. Nevertheless, we assume that old workers are not endowed with the required characteristics to become productive in a young worker position. That is, we are assuming that within the firm's organization all characteristics are not perfectly substitutable. For example, for a given productivity level, the organizational process of the firm may require more physical effort if the job is directed to a young worker and more experience if directed to a senior. Under these assumptions, the decentralized allocation with directed search is a stable equilibrium ${ }^{7}$. However, when directing the vacancy to a young worker the firm interiorizes the fact that the worker will become old with a probability $\lambda_{y}$.

New jobs embody the most advanced known technology. However, once created, their productivity remains constant for the rest of their life. Job creation commits the firm to the technology

\footnotetext{
${ }^{7}$ See Cheron, Hairault, and Langot (2007) for a complete discussion on the equilibrium instability with direct search when all the workers have the same characteristics.
} 
Figure 2: Labor flows.

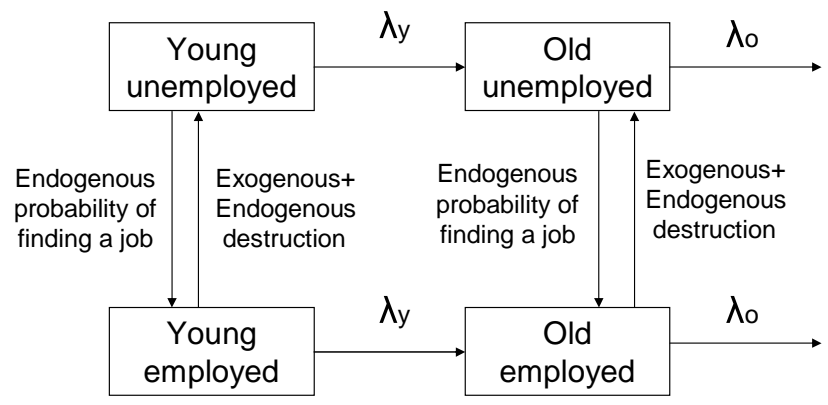

available at that date. Independently on whether a vacancy is directed to a young or to an old worker, a firm without a worker advertises a job vacancy at a cost $p(t) c$ per period, where $p(t)=e^{g t}$ is a common growth factor and $g$ is the rate of productivity growth at the technological frontier (creation costs must grow at rate $g$ to ensure the existence of a steady state with balanced growth). Across newly created jobs, match productivity thus grows at the exogenous rate $g=\dot{p}(t) / p(t)$ (new jobs always embody the most advanced known technology). Once the job is created at date $\tau$ its associated productivity, $p(\tau) x$ does not change ( $x$ is constant). The opportunity cost of unemployment is represented by $p(t) b$. Because the outside option of employment increases in response to productivity growth at the technological frontier whereas the job's productivity remains constant, the surplus associated with a match is decreasing over time.

Once the job is created several situations may arise. First, the firm can continue to produce with the same technology embodied in the job at the creation date. Secondly, the firm may decide to pay a fixed renovation cost to update the technology and continue producing with the same worker. Finally, the firm may decide to close down and exit production because the job is no longer profitable. To keep our representation as close as possible to Mortensen and Pissarides (1998) we will also assume that jobs might be destroyed by an exogenous shock with probability $\delta$.

\subsection{The agents' behavior}

An open vacancy can remain empty or be filled and become productive. The associated asset value for each of these situations is represented by $V_{i}(t)$ for $i=y, o$ if the vacancy is empty at current date $t . \quad J_{i}(\tau, t)$ for $i=y, o$ stands for the value of an existing job at date $t$ which was created at time $\tau$. Similarly, the value of employment in a job at date $t$ which was created at 
time $\tau$ is represented by $W_{i}(\tau, t)$ for $i=y$, whereas the value of unemployment at date $t$ is given by $U(t)$. We first consider the case where the renovation cost is so high that the firm waits for obsolescence rather than ever updating the technology.

\subsubsection{The firms}

When the firm opens a vacancy at date $t$ it bears a cost $p(t) c$, whatever the type of worker, young or old, required to fill the vacancy. There is then a probability $1-q\left(\theta_{i}\right)$ for $i=y, o$ that the vacancy remains empty next period. On the other hand, there is a probability $q\left(\theta_{i}\right)$ for $i=y, o$ that the vacancy gets filled. The asset value associated with a vacancy is then:

$$
r V_{i}(t)=-p(t) c+q\left(\theta_{i}\right)\left(J_{i}(t, t)-V_{i}(t)\right)+\dot{V}_{i}(t) \quad \forall i=y, o
$$

In the equilibrium the firm opens vacancies until all rents are exhausted, i.e. $V_{i}(t)=0$. Market tightness at date $t$ then satisfies:

$$
\frac{p(t) c}{q\left(\theta_{i}\right)}=J_{i}(t, t) \quad \forall i=y, o
$$

Even though we do not assume productivity differentials between young and old workers, the asset value at date $t$ of a job filled at date $\tau$ varies depending on whether the job is directed to a young or to an old worker. In the former case, if at date $\tau$ the worker filling the vacancy is young, the firm interiorizes the fact that the worker horizon before retirement is longer than if the job is occupied by an old worker.

The asset values associated with a job filled by a young worker and by an old worker are respectively given by:

$$
\begin{aligned}
& r J_{y}(\tau, t)=\max \left\{\begin{array}{r}
p(\tau) x-w_{y}(\tau, t)-\delta J_{y}(\tau, t) \\
-\lambda_{y}\left(J_{y}(\tau, t)-J_{o}(\tau, t)\right) \\
+\dot{J}_{y}(\tau, t) \quad, 0
\end{array}\right\} \\
& r J_{o}(\tau, t)=\max \left\{\begin{array}{r}
p(\tau) x-w_{o}(\tau, t)-\left(\delta+\lambda_{o}\right) J_{o}(\tau, t) \\
+\dot{J}_{o}(\tau, t) \quad, 0
\end{array}\right\}
\end{aligned}
$$

where $w_{i}(\tau, t)$ for $i=y, o$ stands for the wage paid at date $t$ in a job created at date $\tau$. When the worker is old the asset value of the filled vacancy must take into account the fact that the worker will retire with probability $\lambda_{o}$. So, for the older workers, aging implies that the continuation value is equal to zero. In contrast, for the young worker, aging leads to a strictly positive continuation value $\left(J_{y}(\tau, t)\right)$. 


\subsubsection{The workers}

An unemployed worker receives a flow of earnings $p(t) b$ including unemployment benefits, leisure, domestic productivity, etc. and increasing with the productivity growth at the technology frontier. A young job seeker comes into contact with a vacant slot at rate $p\left(\theta_{y}\right)=\theta_{y} q\left(\theta_{y}\right)$ and becomes old with probability $\lambda_{y}$. Old job seekers enter into contact with a vacancy at rate $p\left(\theta_{o}\right)=\theta_{o} q\left(\theta_{o}\right)$ and they quit the labor market with probability $\lambda_{o}$. The asset value of unemployment to both types of worker is respectively given by:

$$
\begin{aligned}
& r U_{y}(t)=p(t) b+\theta_{y} q\left(\theta_{y}\right)\left(W_{y}(t, t)-U_{y}(t)\right)-\lambda_{y}\left(U_{y}(t)-U_{o}(t)\right)+\dot{U}_{y}(t) \\
& r U_{o}(t)=p(t) b+\theta_{o} q\left(\theta_{o}\right)\left(W_{o}(t, t)-U_{o}(t)\right)-\lambda_{o} U_{o}(t)+\dot{U}_{o}(t)
\end{aligned}
$$

At date $t$, a job created at $\tau$ and filled by a young worker has a productivity $p(\tau) x$ and pays a wage $w_{y}(\tau, t)$ to the worker. If the job is filled by an old worker, the productivity also equals $p(\tau) x$ and we denote the wage as $w_{o}(\tau, t)$. The present value of a young and an old worker solves:

$$
\begin{aligned}
& r W_{y}(\tau, t)=\max \left\{\begin{array}{r}
w_{y}(\tau, t)-\delta\left(W_{y}(\tau, t)-U_{y}(t)\right) \\
-\lambda_{y}\left(W_{y}(\tau, t)-W_{o}(\tau, t)\right) \\
+\dot{W}_{y}(\tau, t) \quad, U_{y}(t)
\end{array}\right\} \\
& r W_{o}(\tau, t)=\max \left\{\begin{array}{r}
w_{o}(\tau, t)-\delta\left(W_{o}(\tau, t)-U_{o}(t)\right) \\
-\lambda_{o} W_{o}(\tau, t) \\
+\dot{W}_{o}(\tau, t) \quad, U_{o}(t)
\end{array}\right\}
\end{aligned}
$$

Notice that we assume that the asset value corresponding to the retirement period is equal to zero. Without choice of the retirement age and heterogeneity of retirement value between unemployed and employed workers, this simplification does not change the results presented in the paper.

\subsubsection{The wage bargaining process}

Recent works by Pissarides and Vallanti (2007), Mortensen and Nagypal (2007) and Nagypal (2007) adopt the rigid wage definition proposed by Hall and Milgrom (2008). The idea behind the wage determination process proposed by these authors is the following: we suppose that the worker receives a payoff $p(t) b$ in case negotiation breaks down but also when the agreement is delayed. For the firm, we assume that there is no cost while bargaining continues. Firms 
and workers renegotiate the division of the match product $p(\tau) x$, so that the outcome of the symmetric alternating-offers game is :

$$
w_{i}(\tau, t)=\eta p(\tau) x+(1-\eta) p(t) b=p(\tau) \eta x+(1-\eta) p(t) b
$$

The central result of this bargaining process is that the real wage does not depend on the labor market tightness. So, the real wage is rigid.

\section{Creative job destruction: why does growth does not discrim- inate against old workers?}

We assume wages to be independent from the labor market tightness (they are rigid) However, to test the robustness of the results, we will systematically compare our predictions to those obtained under the hypothesis of flexible wages (developed in the Appendix).

When the firm hires a young (an old) worker, it knows that the worker will become old (retire) with probability $\lambda_{y}\left(\lambda_{o}\right)$. Therefore, when actualizing the flow of future profits generated by the job, it interiorizes this probability.

$$
\begin{aligned}
J_{y}(\tau, t)= & \max _{T_{y}}\left\{\int_{t}^{\tau+T_{y}}\left[p(\tau) x-w_{y}(\tau, s)\right] e^{-\left(r+\delta+\lambda_{y}\right)(s-t)} d s\right. \\
& \left.+\lambda_{y} \int_{t}^{\tau+T_{y}} J_{o}(\tau, s) e^{-\left(r+\delta+\lambda_{y}\right)(s-t)} d s\right\} \\
J_{o}(\tau, t)= & \max _{T_{o}}\left\{\int_{t}^{\tau+T_{o}}\left[p(\tau) x-w_{o}(\tau, s)\right] e^{-\left(r+\delta+\lambda_{o}\right)(s-t)} d s\right\}
\end{aligned}
$$

where the wage is given by (11).

Given a stationary time path for future labor market tightness, we conjecture that the value of a new job is proportional to productivity on the technology frontier, i.e. $J_{i}(t, t)=p(t) J$. Replacing in the previous expression when $\tau=t=0$ confirms this conjecture and yields our job destruction rule:

$$
\begin{aligned}
J_{y} & =\max _{T_{y}}\left\{(1-\eta) \int_{0}^{T_{y}}\left[x-e^{g s} b\right] e^{-\left(r+\delta+\lambda_{y}\right) s} d s+\lambda_{y} \int_{0}^{T_{y}} J_{o}(0, s) e^{-\left(r+\delta+\lambda_{y}\right) s} d s\right\} \\
J_{o} & =\max _{T_{o}}\left\{(1-\eta) \int_{0}^{T_{o}}\left[x-e^{g s} b\right] e^{-\left(r+\delta+\lambda_{o}\right) s} d s\right\}
\end{aligned}
$$

Replacing $J_{i}(t, t)=p(t) J$ in the free entry condition (4) confirms that the labor market tightness is stationary, for $i=y, o$ :

$$
\frac{c}{q\left(\theta_{i}\right)}=J_{i}
$$


where we refer to this expression as the job creation rule.

The job destruction curve is a horizontal line in the space $\left(\theta_{i}, J_{i}\right)$ whereas the job creation curve is positively sloped, determining a unique intersection point $\left(\theta_{i}^{*}, J_{i}^{*}\right)$ that stands for the equilibrium in segment $i=y, o$. Evidently, to be economically meaningful these equilibrium values should be positive, which requires $b$ and $c$ to be sufficiently small.

Property 1a The equilibrium optimal age of job destruction does not depend on the age of the workers when wages are rigid.

Proof The equilibrium optimal age of job destruction is the solution to the problems defined on the right hand side of equations (14) and (15):

$$
\begin{aligned}
e^{g T_{y}^{*}} & =\frac{x}{b}\left[1+\lambda_{y} \int_{T_{y}^{*}}^{T_{o}^{*}}\left(1-e^{g\left(s-T_{o}^{*}\right)}\right) e^{-\left(r+\delta+\lambda_{o}\right)\left(s-T_{y}^{*}\right)} d s\right] \\
e^{g T_{o}^{*}} & =\frac{x}{b}
\end{aligned}
$$

Equations (17) and (18) imply that $T_{y}^{*} \geq T_{o}^{*}$ if $\int_{T_{y}^{*}}^{T^{*}}\left(1-e^{g\left(s-T_{o}^{*}\right)}\right) e^{-\left(r+\delta+\lambda_{o}\right)\left(s-T_{y}^{*}\right)} d s$ was positive, which cannot be the case if $T_{y}^{*} \geq T_{o}^{*}$. Hence, there is only one possible solution: $T_{y}^{*}=T_{o}^{*} \equiv T^{*}$. This yields the following expression for the scrapping time for $i=y, o$ :

$$
T^{*}=\frac{\ln x-\ln b}{g}
$$

showing that the scrapping time does not depend on the age of the workers.

Replacing (19) in the job destruction curves permits us to obtain the relationship between $J_{i}^{*}$ and $T_{i}^{*}$ for $i=y, o$ :

$$
\begin{aligned}
J_{y}^{*} & =x(1-\eta) \int_{0}^{T^{*}}\left[1-e^{g\left(s-T^{*}\right)}\right] e^{-\left(r+\delta+\lambda_{y}\right) s} d s+\lambda_{y} \int_{0}^{T^{*}} J_{o}(0, s) e^{-\left(r+\delta+\lambda_{y}\right) s} d s \\
J_{o}^{*} & =x(1-\eta) \int_{0}^{T^{*}}\left[1-e^{g\left(s-T^{*}\right)}\right] e^{-\left(r+\delta+\lambda_{o}\right) s} d s
\end{aligned}
$$

because $J_{o}\left(0, T^{*}\right)=0$ at the equilibrium.

Property 1b The equilibrium value of a young worker job is higher than the equilibrium value of an old worker job. This implies that the hiring rate for young workers is higher than the hiring rate for seniors. 
Proof Equations (20) and (21) clearly show that $J_{y}^{*}>J_{o}^{*}$ when $\lambda_{y}=\lambda_{o}$. The gap between $J_{y}^{*}$ and $J_{o}^{*}$ increases when $\lambda_{y}>\lambda_{o}$, the assumption retained in the paper. Because the job creation curve (equation 16) is an increasing relation between $\theta_{i}$ and $J_{i}$, we deduce that $\theta_{y}>\theta_{o}$.

When wages are flexible, the equilibrium optimal ages of job destruction are given by:

$$
\begin{aligned}
e^{g T_{o}^{*}} & =\frac{x}{\omega\left(\theta_{o}\right)} \\
e^{g T_{y}^{*}} & =\frac{x}{\omega\left(\theta_{y}\right)}+\frac{\lambda_{y}}{(1-\eta) \omega\left(\theta_{y}\right)} J_{o}\left(0, T_{y}^{*}\right)
\end{aligned}
$$

where $J_{o}\left(0, T_{y}^{*}\right)=(1-\eta) \int_{T_{y}^{*}}^{T^{*}}\left(x-e^{g w} \omega\left(\theta_{o}\right)\right) e^{-\left(r+\delta+\lambda_{o}\right) w} d w$, and $T_{o}^{*}$ is known from the old segment. It is easy to show that $T_{i}^{*}$ decreases with $\theta_{i}$, for $i=y, o$.

Property 1c As soon as wages are influenced by labor market conditions, the equilibrium scrapping time of old and young workers differs. In this case, the only consistent equilibrium is such that: $T_{y}^{*}<T_{o}^{*}, J_{y}^{*}>J_{o}^{*}$ and then $\theta_{y}^{*}>\theta_{o}^{*}$.

Proof See Appendix 8.

In summary, the equilibrium in the labor market is characterized by a larger creation rate of young positions than of senior positions, independently of the hypothesis made on the wage determination process. Concerning the endogenous destruction rate, results differ depending on the way wages are determined. In the presence of rigid wages, the age of workers does not introduce any heterogeneity since the deterministic wage growth is shared by the two populations. Then, given the particular vintage of a technology introduced at date $\tau$, the waiting time for obsolescence is the same for young and old workers. In contrast, if wages are flexible, the scrapping time differs between both workers categories, young worker having a shorter scrapping horizon.

Property 2a When the growth rate of the technical progress increases ( $\uparrow g$ )

(i) The optimal scrapping time $T^{*}$ decreases.

(ii) This leads to a decrease in both $J_{y}^{*}$ and $J_{o}^{*}$ and then to less hirings.

(iii) The impact of an increase in the growth rate of technical progress is greater for young workers due to their longer time horizon. Then, when the retirement age is high $\left(\lambda_{o}\right.$ low), the negative impact of the growth is smaller for the old than for the young workers. 
Proof Concerning (i), the impact on the scrapping time is negative (see equation (19)): the direct effect of $g$ on $T^{*}$ tends to reduce the optimal time the firm keeps a technology. Indeed, an acceleration in the pace of technological progress leads the firm to destroy jobs more often in order to adopt the new technology. Then we deduce that $\frac{\partial T^{*}}{\partial g}<0$.

Concerning (ii), in none of the segments is the job creation curve affected. The only observed shift in the $(\theta, J)$ space (for a constant scrapping time) corresponds to the job destruction curve which moves downwards:

- In the old segment:

$$
\left.\frac{\partial J_{o}}{\partial g}\right|_{T=c t e}=\int_{0}^{T}\left(-s e^{g s} b\right) e^{-\left(r+\delta+\lambda_{o}\right) s} d s<0
$$

- In the young segment:

$$
\begin{aligned}
\left.\frac{\partial J_{y}}{\partial g}\right|_{T=c t e}= & \int_{0}^{T}\left(-s e^{g s} b\right) e^{-\left(r+\delta+\lambda_{y}\right) s} d s \\
& +\lambda_{y} \int_{0}^{T} \frac{\partial J_{o}(0, s)}{\partial g} e^{-\left(r+\delta+\lambda_{y}\right) s} d s<0
\end{aligned}
$$

Because faster growth shifts down the horizontal job destruction curves and does not affect the positive relation between $\theta_{i}$ and $J_{i}$ defined by the job creation curves, both the equilibrium value of the match surplus and the labor market tightness decline with growth, i.e. $\frac{\partial J_{i}}{\partial g}<0$ and $\frac{\partial \theta_{i}}{\partial g}<0$ for $i=y, o$.

Part (iii) can be deduced from (24) and (25). Indeed, at the limit, we have $\lambda_{y}=\lambda_{o}$ : in this case, $\left.\left|\frac{\partial J_{o}}{\partial g}\right|_{T=c t e}|<| \frac{\partial J_{y}}{\partial g}\right|_{T=c t e} \mid$. Because we assume $\lambda_{y}<\lambda_{o}$, we have $\left.\left|\frac{\partial J_{o}}{\partial g}\right|_{T=c t e}|<| \frac{\partial J_{y}}{\partial g}\right|_{T=c t e} \mid$. As proved in the Appendix, these results remain robust when considering flexible wages.

In property $1 b$, we showed that, at the equilibrium, the hiring rate for young workers was greater than that of old workers, $J_{y}^{*}>J_{o}^{*}$. Property 2 a suggests that an increase in the growth rate of technical progress decreases the comparative advantage of young workers. Indeed, a higher growth rate fosters a higher labor cost for a longer period of time if the employee is young than if the employee is old. Can we then deduce that growth discriminates against young workers? This result would be completely counterfactual. We can then conclude again that we are not taking into account an impact mechanism: the creative destruction process is not able on its own to explain the link between growth and unemployment. 


\section{Renovation: why do firms prefer to fire old workers?}

We introduce now the possibility for the firm of renovating its technology: the firm pays a fixed cost giving access to the best possible technology. This assumption leads to less caricatural results: with renovation, the creative-destruction process is not the only link between employment and growth. By introducing the possibility of updating, we allow firms to increase their expected profits by incorporating new technologies: if renovation costs are low, one can expect that the "capitalization" effect dominates the "creative-destruction" process. Does this hold for all age categories? More precisely, is the updating decision related to age?

The possibility of updating a technology at date $t$ is possible after incurring a fixed cost $p(t) I$ that allows the firm to increase the value of a job from $J_{i}^{R}(\tau, t)$ to $J_{i}^{R}(t, t)$ for $i=y, o$. Under a fixed renovation cost, the firm that chooses to renovate always moves to the current technology frontier. This renovation cost stands for the sum of both the costs of new equipment and the costs of training.

In this new framework, a job can then be destroyed by an exogenous shock, by an endogenous decision of the firm (if the relation becomes non profitable) or the technology of the job may be updated if the firm pays a fixed renovation cost $p(t) I$ (rather than destroying the job and creating a new one, it may be more profitable for the firm to renovate). Evidently, renovation takes place if and only if the renovation horizon $T_{i}^{R}$ for $i=y, o$ is smaller than the destruction horizon $\left(T_{i}^{R}<T_{i}^{*}\right.$ for $\left.i=y, o\right)$. When renovation occurs, the firm pays an implementation cost $p\left(\tau+T_{i}^{R}\right) I$ for $i=y, o$ in order to raise the value of the job from $J_{i}^{R}\left(\tau, \tau+T_{i}^{R}\right)$ to $J_{i}^{R}\left(\tau+T_{i}^{R}, \tau+T_{i}^{R}\right)$ for $i=y, o$.

The value of a filled job when renovation is possible is given by:

$$
\begin{aligned}
J_{o}^{R}(\tau, t)= & \max _{T_{o}^{R}}\left\{\int_{t}^{\tau+T_{o}^{R}}[p(\tau) x-\eta p(\tau) x-(1-\eta) p(t) b] e^{-\left(r+\delta+\lambda_{o}\right)(s-t)} d s\right. \\
& \left.+e^{-\left(r+\delta+\lambda_{o}\right)\left(\tau+T_{o}^{R}-t\right)}\left[J_{o}^{R}\left(\tau+T_{o}^{R}, \tau+T_{o}^{R}\right)-p\left(\tau+T_{o}^{R}\right) I\right]\right\}
\end{aligned}
$$

for a senior, and

$$
\begin{aligned}
J_{y}^{R}(\tau, t)= & \max _{T_{y}^{R}}\left\{\int_{t}^{\tau+T_{y}^{R}}[p(\tau) x-\eta p(\tau) x-(1-\eta) p(t) b] e^{-\left(r+\delta+\lambda_{y}\right)(s-t)} d s\right. \\
& +e^{-\left(r+\delta+\lambda_{y}\right)\left(\tau+T_{y}^{R}-t\right)}\left[J_{y}^{R}\left(\tau+T_{y}^{R}, \tau+T_{y}^{R}\right)-p\left(\tau+T_{y}^{R}\right) I\right] \\
& \left.+\lambda_{y} \int_{t}^{\tau+T_{y}^{R}} J_{o}^{R}(\tau, s) e^{-\left(r+\delta+\lambda_{y}\right)(s-t)} d s\right\}
\end{aligned}
$$


for a young worker.

As $J_{i}^{R}(t, t)=p(t) J_{i}^{R}$, when $\tau=t=0$ we obtain:

$$
\begin{aligned}
J_{o}^{R}= & \max _{T_{o}^{R}}\left\{(1-\eta) \int_{0}^{T_{o}^{R}}\left[x-e^{g s} b\right] e^{-\left(r+\delta+\lambda_{o}\right) s} d s+e^{-\left(r+\delta+\lambda_{o}-g\right) T_{o}^{R}}\left[J_{o}^{R}-I\right]\right\} \\
J_{y}^{R}= & \max _{T_{y}^{R}}\left\{(1-\eta) \int_{0}^{T_{y}^{R}}\left[x-e^{g s} b\right] e^{-\left(r+\delta+\lambda_{y}\right) s} d s+e^{-\left(r+\delta+\lambda_{y}-g\right) T_{y}^{R}}\left[J_{y}^{R}-I\right]\right. \\
+ & \left.\lambda_{y} \int_{0}^{T_{y}^{R}} J_{o}^{R}(0, s) e^{-\left(r+\delta+\lambda_{y}\right) s} d s\right\}
\end{aligned}
$$

These new job destruction curves remain horizontal lines in the $\left(\theta_{i}^{R}, J_{i}^{R}\right)$ space for $i=y, o$, whereas we have the same positive sloped job creation curves defined in equation (16), leading to a unique labor market equilibrium $\left(\theta_{i}^{R *}, J_{i}^{R *}\right)$ for $i=y, o$.

The optimal choice of the renovation horizon is obtained solving the right hand side problem of equations (27) and (28):

$$
\begin{aligned}
b & =\frac{x}{e^{g T_{o}^{R *}}}-\left(J_{o}^{R}-I\right) \frac{\left(r+\delta+\lambda_{o}-g\right)}{1-\eta} \\
b & =\frac{x}{e^{g T_{y}^{R *}}}-\frac{\left(r+\delta+\lambda_{y}-g\right)}{1-\eta}\left(J_{y}^{R}-I\right)+\frac{\lambda_{y}}{e^{g T_{y}^{R *}}(1-\eta)} J_{o}^{R}\left(0, T_{y}^{R *}\right)
\end{aligned}
$$

Replacing in equation (27) and (28) yields the optimal date at which the firm decides to renovate:

$$
\begin{aligned}
I= & x(1-\eta) \int_{0}^{T_{o}^{R *}}\left[1-e^{g\left(s-T_{o}^{R *}\right)}\right] e^{-\left(r+\delta+\lambda_{o}\right) s} d s \\
I= & x(1-\eta) \int_{0}^{T_{y}^{R *}}\left[1-e^{g\left(s-T_{y}^{R *}\right)}\right] e^{-\left(r+\delta+\lambda_{y}\right) s} d s \\
& +\lambda_{y} \int_{0}^{T_{y}^{R *}}\left[J_{o}^{R}(0, s)-e^{g\left(s-T_{y}^{R *}\right)} J_{o}^{R}\left(0, T_{y}^{R *}\right)\right] e^{-\left(r+\delta+\lambda_{y}\right) s} d s
\end{aligned}
$$

Property 3a The optimal date at which the firm decides to renovate a position occupied by an old worker ${ }^{8}\left(T_{o}^{R *}\right)$ is an increasing function of the fixed renovation cost $(I)$ and the probability of the worker becoming a retiree $\left(\lambda_{0}\right)$. On the other hand, $T_{o}^{R *}$ decreases with the growth rate of technical progress $(g)$.

Proof See equation (31). This result remains robust in the presence of flexible wages (see Appendix 8).

\footnotetext{
${ }^{8}$ The optimal date at which the firm decides to renovate a position occupied by a young worker $\left(T_{y}^{R *}\right)$ is an increasing function of the fixed renovation cost $(I)$ and of the probability of the worker becoming a retiree. On the other hand, $T_{y}^{R *}$ decreases with the growth rate of technical progress $(g)$. See equation (32), given that $\partial J_{o}^{R}(\tau, t) / \partial \lambda_{o}<0$.
} 
It is in the interest of the firm to renovate if and only if the renovation cost is lower than the optimal value it obtains without renovation:

$$
\begin{aligned}
& I \leq J_{o}^{*} \Leftrightarrow T_{o}^{R *}<T^{*} \quad \text { for a senior } \\
& I \leq J_{y}^{*} \Leftrightarrow T_{y}^{R *}<T^{*} \quad \text { for a young worker }
\end{aligned}
$$

Because $J_{y}^{*}>J_{o}^{*}$ (given the equality in the obsolescence age), the firm may face a situation where the updating cost $I$ is such that $J_{y}^{*}>I>J_{o}^{*}$. That is, it is in the interest of the firm to update only if the worker is young. For old workers it is not profitable to renovate and the firm prefers to fire the worker and open a new vacancy ${ }^{9}$.

However, the firm can also face a situation where it is in its interest to update jobs occupied by young and old workers, i.e. $J_{y}^{*}>J_{o}^{*}>I$. In this case, does technical progress help old workers? Not necessarily, because the impact of an acceleration in $g$ is ambiguous ${ }^{10}$. If the implementation cost is close to zero, we have a pure "capitalization" effect: the destruction is reduced to its exogenous component and the technology is renovated continuously as in the Solow model. If the renovation cost is high, the pure "creative-destruction" process is at work. Between these two extremes cases, there is a unique critical up-dating cost such that the creative destruction effect offsets the capitalization effect. So, if $I$ is lower (higher) than this threshold value of the renovation cost, faster growth leads to more (less) job creation: the capitalization (creative-destruction) effect dominates.

The predominance of the capitalization effect when $I$ becomes very small, can be interpreted in two ways. First, we can focus on the specific abilities of the workers. If the skills of an old worker are close to the abilities required by new jobs, the training cost is low and then the renovation strategy is optimal. In contrast, if the gap between the worker's skills and the abilities required by the firm is large, the renovation cost is high: the optimal strategy is to fire the worker because search costs are lower than training $\operatorname{costs}^{11}$. Secondly, we can focus on the sector-specific investment costs. In sectors where the cost of new equipment is low, the

\footnotetext{
${ }^{9}$ This result is moderated if we introduce the possibility of heterogeneous productivity among old workers. As shown in the Appendix, in this situation it may be in the interest of the firm to update positions occupied by old qualified workers.

${ }^{10}$ The ambiguity of the the impact $g$ on the job creation appear in in both an economy with rigid wages and in an economy with flexible wages.

${ }^{11}$ This finding is confirmed when working with the French Complementary Survey on Training 2001. When we consider workers above 50 years old, specific human capital investment paid by firms is biased in favor of some types of occupations, referred to as "high productivity occupations". Around $44 \%$ of managers (38\% of technicians)
} 
probability of renovating a job occupied by an old worker is higher than in sectors where the investment cost is high ${ }^{12}$. If we introduce match-heterogeneity in our basic model, we find that the renovation strategy and the optimal scrapping time depend on a match-specific productivity component (see the Appendix). This extension of our basic set-up allows us to account for the observed large heterogeneity measured with micro-data.

What about the impact of the retirement age? Does a low retirement age discriminate against old workers? As the optimal renovation date increases with the probability of retirement, $\partial T_{o}^{R *} / \partial \lambda_{0}>0$, we are less likely to find $T_{o}^{R *}<T^{*}$ when the impending retirement age is low. Indeed, for a high probability of retirement, $\lambda_{o}$, the horizon of the worker is shorter. The probability of recouping the renovation cost is then lower than in an economy characterized by a higher retirement age (low $\lambda_{o}$ ). Furthermore since $\partial J_{o}^{*} / \partial \lambda_{o}<0$ the renovation condition $I \leq J_{o}^{*}$ also becomes less likely. The increase in $\lambda_{o}$ then reduces the probability of updating ${ }^{13}$. So, a short horizon before the retirement age leads to more weighting of the creative-destruction effect.

\section{The young and old unemployment rates}

At the steady state, we must find that, in each of the two labor market segments (young and old), job creation flows must equal job destruction flows. In the economy, jobs are destroyed either because they experience an exogenous job destruction shock or because they reach the between 51 and 55 years old and $34 \%$ of those ( $21 \%$ of technicians) between 56 and 60 years old receives training paid by the firm in the case of technological change. When considering employees, these percentages are reduced to $21 \%$ and $9 \%$, and to $13 \%$ and $8 \%$ for manual workers. In spite of their shorter working horizon, firms continue to invest in managers' and technicians' specific human capital (rather than in that of employees and manual workers), suggesting that the productivity gains obtained by updating their skills manage to compensate for the training cost.

${ }^{12}$ Again, this result is clearly observed in the French data for the period 1996-2004, where we estimate that the average share of exits for workers aged above 50 is almost $23 \%$ per year in the industry whereas in the service sector it falls to $13 \%$.

${ }^{13}$ This effect is less clear in the presence of flexible wages, since the increase in the optimal renovation date is also associated with the increase in the scrapping time, so at the end we might have $T_{o}^{R *} \gtrless T_{o}^{*}$. Because wages are flexible, we might find that the fall in wages is sufficiently steep to induce a rise in the scrapping time such that the final updating horizon $T_{o}^{R *}$ remains lower than $T_{o}^{*}$. In this case it will be in the interest of the firm to update rather than to destroy the job (under the assumption that $I<J_{o}^{*}$ ), in spite of the increased probability of retirement. 
age of obsolescence. When considering the young segment we will also have to take into account the flows of entry into unemployment coming from "new born". And when focusing on the old segment we will have to consider the entries to unemployment coming from the young segment. Let us first consider the exits and entries to unemployment in the young segment. The former correspond to the rate at which workers are matched with jobs plus the fraction of unemployed young workers becoming old, that is: $O U T_{y}=p\left(\theta_{y}\right) u_{y}+\lambda_{y} u_{y}$. Entries to unemployment come from new born, $\lambda_{o} P_{o}$, exogenous job destruction, $\delta\left(P_{y}-u_{y}\right)$ and from the fraction of job creation that survives in the same age-class (young) to exogenous destruction, $p\left(\theta_{y}\right) u_{y} e^{-\left(\delta+\lambda_{y}\right) T^{*}}$. Then, we have $I N_{y}=\delta\left(P_{y}-u_{y}\right)+p\left(\theta_{y}\right) u_{y} e^{-\left(\delta+\lambda_{y}\right) T^{*}}+\lambda_{o} P_{o}$. At the steady state entries and exits from unemployment are equalized, leading to the following equilibrium young unemployment rate (because the young work force is normalized to one, $u_{y}$ now stands for a rate):

$$
\begin{aligned}
\underbrace{p\left(\theta_{y}\right) u_{y}+\lambda_{y} u_{y}}_{\text {OUT }} & =\underbrace{\delta\left(P_{y}-u_{y}\right)+p\left(\theta_{y}\right) u_{y} e^{-\left(\delta+\lambda_{y}\right) T^{*}}+\lambda_{o} P_{o}}_{I N_{y}} \\
\Rightarrow u_{y} & =\frac{\delta+\lambda_{y}}{\delta+\lambda_{y}+\left(1-e^{-\left(\delta+\lambda_{y}\right) T^{*}}\right) p\left(\theta_{y}\right)}
\end{aligned}
$$

So, the employment rate of the young worker is $n_{y}=1-u_{y}$.

The reasoning is fairly similar for the old segment. The flows out from unemployment are given by $O U T_{o}=p\left(\theta_{o}\right) u_{o}+\lambda_{o} u_{o}$, where $\lambda_{o} u_{o}$ stands for people retiring. The flows of entries to unemployment are given by: $I N_{o}=\delta\left(P_{o}-u_{o}\right)+p\left(\theta_{o}\right) u_{o} e^{-\left(\delta+\lambda_{o}\right) T^{*}}+\lambda_{y} u_{y}+\frac{\lambda_{y}}{\delta+\lambda_{y}} u_{y} p\left(\theta_{y}\right) e^{-\left(\delta+\lambda_{y}\right) T^{*}}$. 
Equalizing entries ${ }^{14}$ and exits and dividing by $P_{o}$ yields the following equilibrium unemployment rate:

$$
\begin{aligned}
\underbrace{p\left(\theta_{o}\right) u_{o}^{R}+\lambda_{o} u_{o}^{R}}_{\text {OU } T_{o}}= & \underbrace{\delta\left(1-u_{o}^{R}\right)+p\left(\theta_{o}\right) u_{o}^{R} e^{-\left(\delta+\lambda_{o}\right) T^{*}}+\frac{\lambda_{o}}{\delta+\lambda_{y}} u_{y} p\left(\theta_{y}\right) e^{-\left(\delta+\lambda_{y}\right) T^{*}}+\lambda_{o} u_{y}}_{I N_{o}} \\
\Rightarrow u_{o}^{R} & =\frac{\delta+\lambda_{o} u_{y}+\frac{\lambda_{o}}{\delta+\lambda_{y}} u_{y} p\left(\theta_{y}\right) e^{-\left(\delta+\lambda_{y}\right) T^{*}}}{\delta+\lambda_{o}+\left(1-e^{-\left(\delta+\lambda_{o}\right) T^{*}}\right) p\left(\theta_{o}\right)}
\end{aligned}
$$

So, the employment rate of the old worker is $n_{o}=1-u_{o}$.

When all jobs are updated, the only source of destruction is the exogenous shock represented by $\delta$, so that the young and old unemployment rates are respectively given by $u_{y}=\frac{\delta+\lambda_{y}}{\delta+\lambda_{y}+p\left(\theta_{y}\right)}$ and $u_{o}^{R}=\frac{\delta+\lambda_{o} u_{y}}{\delta+\lambda_{o}+p\left(\theta_{o}\right)}$.

Finally, note that if the creative-destruction effect dominates in the old labor segment, there are some endogenous destructions, increasing with the TFP growth rate since $\partial T^{*} / \partial g<0$ There will also be less job creations, $\partial \theta_{o} / \partial g<0$. This is, however, not sufficient to ensure that $\partial u_{o} / \partial g>0$. If the capitalization effect dominates in the young labor market segment, there is a mechanical effect coming from the fact that young unemployed workers become old. Therefore, if unemployment decreases in the young segment, it will also fall in the old segment. So, the impact of growth on the employment rate of the older workers remains ambiguous.

\footnotetext{
${ }^{14}$ The term $\frac{\lambda_{y}}{\delta+\lambda_{y}} u_{y} p\left(\theta_{y}\right) e^{-\left(\delta+\lambda_{y}\right) T^{*}}$ stands for those young employed workers who become old and lose their job endogenously. At each time $t$, the flow of young workers employed in a vintage $\tau$ becoming old is defined by:

$$
N_{o}^{y}(\tau, t)=\lambda_{y} u_{y} p\left(\theta_{y}\right) \exp \left(-\left(\delta+\lambda_{y}\right) t\right)
$$
}

The dynamic of employment of the old workers is given by

$$
\dot{N}_{o}(t)=\underbrace{-\left(\delta+\lambda_{o}\right) N_{o}(t)}_{\text {Exo. des. }}-\underbrace{N_{o}\left(t-T_{o}, t\right)}_{\text {Endo. des. }}+\underbrace{\int_{t-T_{o}}^{t} N_{o}^{y}(\tau, t) d \tau}_{\text {Young becoming old }}+\underbrace{u_{o} p\left(\theta_{o}\right)}_{\text {Hirings }}
$$

where

$$
\begin{aligned}
N_{o}\left(t-T_{o}, t\right) & =u_{o} p\left(\theta_{o}\right) \exp \left(-\left(\delta+\lambda_{o}\right) T_{o}\right) \\
\int_{t-T_{o}}^{t} N_{o}^{y}(\tau, t) d \tau & =\int_{t-T_{o}}^{t} \lambda_{y} u_{y}(\tau, t) p\left(\theta_{y}(\tau, t)\right) \exp \left(-\left(\delta+\lambda_{y}\right) \tau\right) d \tau
\end{aligned}
$$

At steady state, we have $u_{y}(\tau, t)=u_{y}$ and $p\left(\theta_{y}(\tau, t)\right)=p\left(\theta_{y}\right)$. Then, we have

$$
\int_{0}^{T_{o}} N_{o}^{y}(\tau) d \tau=\lambda_{y} u_{y} p\left(\theta_{y}\right) \int_{0}^{T_{o}} \exp \left(-\left(\delta+\lambda_{y}\right) \tau\right) d \tau=\lambda_{y} u_{y} p\left(\theta_{y}\right) \frac{1-\exp \left(-\left(\delta+\lambda_{y}\right) T_{o}\right)}{\delta+\lambda_{y}}
$$




\section{Numerical Simulations}

The theoretical analysis shows that there is an equilibrium such that an acceleration of the TFP growth can improve the employment rate of the prime-age workers, and simultaneously discriminate against older workers. This equilibrium is in accordance with the stylized facts. Nevertheless, for all equilibrium configurations, two contradictory effects arise when growth accelerates. On the one hand, faster growth decreases profits more rapidly and then accelerates the "creative-destruction process". On the other hand, faster growth yields a higher expected surplus after renovation occurs, reducing the implementation horizon. Then, even if the capitalization effect dominates in the young labor market segment, the presence of the creative destruction effect moderates the impact of growth on the equilibrium employment rate. In this section, we propose numerical experiments in order to test the ability of the model to reproduce the elasticities estimated in the introduction. These experiments contribute to enriching the discussion on the capacity of the matching model to explain the impact of productivity changes on the employment rate $^{15}$. We only report the outcome of computational experiments for the rigid wage case. Pissarides and Vallanti (2007) paper shows that this assumption improves the elasticity of the employment rate with respect to the TFP growth rate.

Table 2: Baseline Parameters Values

\begin{tabular}{l|rl}
\hline \hline Job productivity & $x$ & $=1$ \\
& Interest rate & $=.04$ \\
Matching elasticity & $\alpha$ & $=.5$ \\
Recruiting cost & $c / q\left(\theta_{y}\right)$ & $=.35$ \\
& Exogenous separation rate \\
Bargaining power & $\eta$ & .032 \\
Outside option & $\eta$ & .5 \\
Young age duration & $b$ & $=3$ \\
Old age duration & $1 / \lambda_{y}$ & $=36$ years \\
\hline \hline
\end{tabular}

\footnotetext{
${ }^{15}$ See Pissarides and Vallanti (2007) for the long-run relationship between TFP growth and employment, or Shimer (2005), Hall (2005), Mortensen and Nagypal (2007), Hagedorn and Manovskii (2008), Costain and Reiter (2008) or Pissarides (2007) for the short-run relationship between productivity shocks and employment fluctuations.
} 
A matching function of the Cobb-Douglas form is assumed: $M=\phi u_{i}^{\alpha} v_{i}^{1-\alpha}$, for $i=y, o$, where $\alpha$ is the elasticity with respect to unemployment and it is assumed to be equal to 0.5 (see Petrongolo and Pissarides (2001)). The numerical values of the parameters of our benchmark simulation are summarized in Table 2. Pissarides and Vallanti (2007) fix the exogenous job destruction rate, $\delta$, according to the values provided in Tables 2.1 and 2.1 in Davis, Haltiwanger, and Schuh (1996) for the period 1973-1988. Our calibration will differ from that used in Pissarides and Vallanti (2007). Instead of using US data, we employ the estimations provided by Gomez-Salvador, Messina, and Vallanti (2004) for France for the period from 1992 to 2000. The estimated annual job destruction rates linked to exits from the manufacturing sector are equal to $3.2 \%$, implying that the life expectancy of an establishment is at least 31 years. The outside option $b=.4$ is chosen on the basis of the estimations made by Blanchard and Wolfers (2000) for France.

Given this set of parameters, we choose the implementation cost $I$ and the scale parameter of the matching function $\phi$, such that we match both the employment rate and the unemployment duration of a European type economy. Our numerical simulations display, for an annual TFP growth rate equal to $2 \%$, an equilibrium employment rate around $90 \%$ for the $25-54$ year old workers (young workers) and an unemployment duration of 1.8 years. For 55-64 year old workers the employment rate equals $39 \%$ and the unemployment duration is six years ${ }^{16}$. Our estimation of the job and the scale parameter of the matching function equals 0.25 and the renovation cost is $60 \%$ of the productivity.

Table 3: The impact of growth on the main macroeconomic variables

\begin{tabular}{c|cccccccc} 
& $n_{y}$ & $n_{o}$ & $T_{y}$ & $T_{y}^{R}$ & $T_{o}$ & $T_{o}^{R}$ & $1 / p\left(\theta_{y}\right)$ & $1 / p\left(\theta_{o}\right)$ \\
\hline \hline$g=2 \%$ & $90.14 \%$ & $38.74 \%$ & 45.81 & 13.49 & 45.81 & 27.62 & 1.83 & 6.29 \\
$g=3 \%$ & $90.29 \%$ & $38.72 \%$ & 30.54 & 10.69 & 30.54 & 19.53 & 1.80 & 6.45 \\
\hline \hline
\end{tabular}

Table 3 reveals many interesting results. First of all, an increase of one percentage point in the TFP growth rate decreases the unemployment duration of young workers while increasing that of old workers. This simply results from the rise in the employment opportunities in the

\footnotetext{
${ }^{16}$ In order to compute an employment rate for the 55-64 years old workers, we assume that the retirement age is equal to 60 , as in the French economy. Then, the employment rate of the 55-59 year old workers is strictly positive. In contrast, the employment rate for the 60-64 year old workers is equal to zero. The employment rate of the 55-64 year old workers is then computed as the weighted average of these employment rates.
} 
young segment and the decrease in the employment opportunities for the old segment. The capitalization effect is then dominant in the young market whereas the creative destruction dominates in the old market. Secondly, it is in the interest of the firms to renovate positions occupied by young and old workers $\left(T_{i}>T_{i}^{R} \forall i=y, o\right)^{17}$. However, the optimal renovation horizon is 13.49 years for the young workers and 27.62 years for the old workers. Given the short working horizon of old workers (the expected duration for a job occupied by an old worker is 4 years) these jobs are certain to have ended before the renovation date. In contrast, young workers can take advantage of the economic growth since their working horizon equals 36 years. Finally, Table 3 shows that an increase of one percentage point in the growth rate increases the employment rate of prime workers by 0.143 percentage points and decreases that of old workers by 0.016 , which remains far away from the empirical estimations provided in Table 1 . The low elasticity of the old-worker employment rate is due to the large impact of the horizon effect: the impact of the endogenous job destruction flows on the employment rate is small because (i) the proportion of the 55-59 age-group in the total population of 55-64 year old workers is one half, and (ii) there is a positive effect coming from the young labor segment where the employment rate increases.

Similarly to Pissarides and Vallanti (2007) or Shimer (2005), we can try to "play" with the parameters so as to increase the elasticity of employment with respect to growth or to productivity shocks. In order to have realistic results we focus on the parameter ${ }^{18}, \alpha$, for which there exists an extensive literature adopting quite different values (see Petrongolo and Pissarides (2001) for a synthesis).

Table 4 reveals that the lowest elasticity (0.143) corresponds to our benchmark simulation, where $b=0.4$ is taken from Blanchard and Wolfers (2000) and $\alpha=0.5$ stands for the intermediate value provided in the estimations of Petrongolo and Pissarides (2001). When the elasticity of the matching process with respect to unemployment is reduced to $\alpha=0.3$, a one percentage point increase in the growth rate increases employment by 0.825 points, which corresponds well to the estimations provided in Table 1. The intuition behind this result is the following one. An increase in the TFP growth rate encourages firms to open more vacancies. However, since for

\footnotetext{
${ }^{17}$ As in Pissarides and Vallanti (2007), the calculated scrapping times are very high, above 45 years for $g=2 \%$ and above 30 years for $g=3 \%$

${ }^{18}$ In Pissarides and Vallanti (2007) the authors find that, in order to reproduce the estimated elasticity of unemployment with respect to growth, $r+\delta$ should equal 0.05. However, this implies adopting completely unrealistic values for $r$ or for $\delta$.
} 
Table 4: Young workers' employment rate elasticity: a sensitivity analysis

\begin{tabular}{cc}
\hline \hline $\bar{\alpha}=0.5$ & $\underline{\alpha}=0.3$ \\
\hline 0.1422 & 0.8251 \\
\hline \hline
\end{tabular}

$I$ and $\phi$ are chosen so that

the young employment rate equals 0.9

and their unemployment duration 1.8

low values of $\alpha$ the probability of filling a vacancy $\left(q(\theta)=m_{0} \theta^{-\alpha}\right)$ is reduced, the number of vacancies posted must be high if firms want to benefit from the increased profit. As a result, it becomes easier for unemployed workers to find a job. Unemployment is then more sensitive to growth when $\alpha$ adopts low values.

Let us now analyze the impact of an early retirement policy. We suppose that the working horizon of an old worker is reduced to two years. As observed in Table 5 this yields a sharp drop in the employment rate of old workers from $39 \%$ to $18 \%$. With this new calibration of the expected time horizon of old workers, it is not in the interest of the firm to renovate positions occupied by old workers, that is, the scrapping horizon is below the implementation horizon. But both horizons are though too high with respect to the short working horizon of these workers. Most of the exits from employment come now from the retirement decision. Actually, we realize that an increase in one percentage point in the TFP growth decreases the employment rate by 1.83 percentage points, which constitutes a sizeable elasticity. This large elasticity is mainly explained by the creation side since the scrapping time remains too high to significantly affect the destruction flows.

Table 5: The impact of an early retirement policy

\begin{tabular}{c|cccccccc} 
& $n_{y}$ & $n_{o}$ & $T_{y}$ & $T_{y}^{R}$ & $T_{o}$ & $T_{o}^{R}$ & $1 / p\left(\theta_{y}\right)$ & $1 / p\left(\theta_{o}\right)$ \\
\hline \hline$g=2 \%$ & $89.72 \%$ & $18.17 \%$ & 45.81 & 13.80 & 45.81 & 59.76 & 1.91 & 10.94 \\
$g=3 \%$ & $89.85 \%$ & $16.34 \%$ & 30.54 & 10.92 & 30.54 & 40.44 & 1.89 & 11.084 \\
\hline \hline
\end{tabular}




\section{Conclusions}

Recent studies on the link between growth and unemployment concur on the existence of a negative relationship between both variables, suggesting that, in the case of an acceleration in the growth rate, the capitalization effect dominates the creative destruction effect (see Blanchard and Wolfers (2000), Pissarides and Vallanti (2007) or Tripier (2007)). However, one of the main drawbacks of these studies is that, by considering homogeneous agents, they are ignoring the heterogenous effects growth may have on different population segments. This paper analyzes the effects of growth on employment along the life cycle, and more precisely, the effects of growth on the employment rate of old workers.

We then present some empirical facts showing that the link between economic growth and the employment rate is age-dependent. In OECD countries, economic growth discriminates against older workers, whereas an acceleration in growth leads to more employment for primeage workers. In order to explain these empirical results, we develop a vintage model inspired by Mortensen and Pissarides (1998) but distinguishing between young and old workers. The introduction of life-cycle features introduces a comparative advantage for young workers: when a worker is young, the time horizon during which a firm can recoup the updating cost of renovating an existing technology is longer than for a senior. So, the firm renovates jobs occupied by young workers, whereas separation is the best strategy if the job is occupied by an old worker. An equilibrium in accordance with the estimated facts is then characterized by a higher (lower) impact of the capitalization effect than the creative destruction effect in the young (old) labor market segment. Contrary to Pissarides and Vallanti (2007), our results suggest that the creative destruction effect is a useful concept in order to explain the link between economic growth and the employment rate by age class.

Our computational experiments confirm this theoretical result. However, even though, with realistic parameter values, we manage to reproduce the positive relationship between growth and the employment rate of young workers and the negative relationship between growth and the employment rate of old workers, the simulated elasticities remain far removed from their empirical counterparts. Several sensitivity analysis are then performed. 


\section{Appendix. Robustness : the wage bargaining}

\subsection{Bargained Wages}

Since search and hiring activities are costly, when a match is formed a joint surplus is generated. At the beginning of every period, the firm and the employee negotiate wages through a Nash bargaining process, which splits the joint surplus into fixed proportions at all times:

$$
\begin{aligned}
S(\tau, t) & =J_{i}(\tau, t)-V_{i}(t)+W_{i}(\tau, t)-U_{i}(t) \\
J_{i}(\tau, t) & =(1-\eta) S(\tau, t) \\
W_{i}(\tau, t)-U_{i}(t) & =\eta S(\tau, t),
\end{aligned}
$$

$\forall i=y, o$, where $\eta \epsilon(0,1)$ is the bargaining power of workers. Replacing equations (3), (5), (6), (7), (8), (9) and (10) in expression (35), and applying then one of the sharing rules (either (36) or (37)) leads to the following wage:

$$
\begin{aligned}
w_{i}(\tau, t) & =\eta p(\tau) x+(1-\eta) p(t)\left(b+\frac{\eta}{1-\eta} c \theta_{i}\right) \\
& =\eta p(\tau) x+(1-\eta) p(t) \omega\left(\theta_{i}\right) \quad \forall i=y, o
\end{aligned}
$$

The wage equals a weighted average of the worker's productivity in her current job and the flow value of her outside options, since $\omega\left(\theta_{i}\right)=\left(b+\frac{\eta}{1-\eta} c \theta_{i}\right)$ represents the worker's reservation wage (the flow value of the worker's job search option). One of the main drawbacks of this specification is that it makes wages dependent on the labor market conditions $\theta^{19}$.

\subsection{The equilibrium with wage bargaining}

Given the wage equation (38) and knowing that the value of a new job is proportional to productivity on the technology frontier, (i.e. $\left.J_{i}(t, t)=p(t) J\right), \forall i=y, o$, job destruction rules are given by:

$$
\begin{aligned}
J_{o}= & \max _{T_{o}}\left\{(1-\eta) \int_{0}^{T_{o}}\left[x-e^{g s} \omega\left(\theta_{o}(s)\right)\right] e^{-\left(r+\delta+\lambda_{o}\right) s} d s\right\} \\
J_{y}= & \max _{T_{y}}\left\{(1-\eta) \int_{0}^{T_{y}}\left[x-e^{g s} \omega\left(\theta_{y}\right)\right] e^{-\left(r+\delta+\lambda_{y}\right) s} d s\right. \\
+ & \left.+\lambda_{y} \int_{0}^{T_{y}} J_{o}(0, s) e^{-\left(r+\delta+\lambda_{y}\right) s} d s\right\}
\end{aligned}
$$

\footnotetext{
${ }^{19}$ Pissarides (2007) shows that the traditional Nash wage equation does well in reproducing the observed volatility in new matches but it implies too much cyclical volatility for the wages in ongoing employment relationships.
} 
As in the wage posting case, the job creation rule is given by (16).

The equilibrium optimal ages of job destruction, are the solution to the problems defined on the right hand side of equations (39) and (40):

$$
\begin{aligned}
e^{g T_{o}^{*}} & =\frac{x}{\omega\left(\theta_{o}\right)} \\
e^{g T_{y}^{*}} & =\frac{x}{\omega\left(\theta_{y}\right)}+\frac{\lambda_{y}}{(1-\eta) \omega\left(\theta_{y}\right)} J_{o}\left(0, T_{y}^{*}\right)
\end{aligned}
$$

where $J_{o}\left(0, T_{y}^{*}\right)=(1-\eta) \int_{T_{y}^{*}}^{T_{0}^{*}}\left(x-e^{g w} \omega\left(\theta_{o}\right)\right) e^{-\left(r+\delta+\lambda_{o}\right) w} d w$, and $T_{o}^{*}$ is known from the old segment. It is easy to show that $T_{i}^{*}$ decreases with $\theta_{i}$, for $i=y, o$.

Replacing (41) and (42) in the job destruction curve permits us to obtain the relationship between $J_{i}^{*}$ and $T_{i}^{*}$, for $i=y, o$ :

$$
\begin{aligned}
J_{o}^{*}= & (1-\eta) x \int_{0}^{T_{o}^{*}}\left[1-e^{g\left(s-T_{o}^{*}\right)}\right] e^{-\left(r+\delta+\lambda_{o}\right) s} d s \\
J_{y}^{*}= & (1-\eta) x \int_{0}^{T_{y}^{*}}\left[1-e^{g\left(s-T_{y}^{*}\right)}\right] e^{-\left(r+\delta+\lambda_{y}\right) s} d s \\
& +\lambda_{y} \int_{0}^{T_{y}^{*}}\left[J_{o}(0, s)-e^{g\left(s-T_{y}^{*}\right)} J_{o}\left(0, T_{y}^{*}\right)\right] e^{-\left(r+\delta+\lambda_{y}\right) s} d s
\end{aligned}
$$

Proof of property $1 c$ We have two cases:

1. If $T_{y}^{*}>T_{o}^{*}$, then $J_{o}\left(0, T_{y}^{*}\right)=0$ since the integral cannot be negative. According to $e^{g T_{o}^{*}}=\frac{x}{\omega\left(\theta_{o}\right)}$ and $e^{g T_{y}^{*}}=\frac{x}{\omega\left(\theta_{y}\right)}$ we should then find that $\theta_{y}^{*}<\theta_{o}^{*}$, which implies $J_{y}^{*}<J_{o}^{*}$ given the free entry condition. This is not possible given equations (43) and (44) for $\lambda_{y} \geq \lambda_{o}$, because $\frac{\partial J_{i}^{*}}{\partial T_{i}^{*}}>0$. So, this case does not correspond to the equilibrium.

2. In contrast, if $T_{y}^{*}<T_{o}^{*}$, one can have $J_{o}\left(0, T_{y}^{*}\right) \geq 0$. For the same value of $\theta\left(\theta_{o}^{*}=\theta_{y}^{*}\right)$, equations (41) and (42) imply that $T_{y}^{*}>T_{o}^{*}$ if $J_{o}\left(0, T_{y}^{*}\right)>0$. Hence, a consistent equilibrium is such that $\theta_{y}^{*}>\theta_{o}^{*}$ in order to compensate for the impact of $J_{o}\left(0, T_{y}^{*}\right)>0$. If $\theta_{y}^{*}>\theta_{o}^{*}$, the job creation rule (equation (16)) leads to $J_{y}^{*}>J_{o}^{*}$.

\subsection{An increase in the growth rate of technical progress}

Property 2b When the growth rate of technological progress accelerates ( $g$ increases): 
(i) There is a decrease in the equilibrium values of $J_{y}^{*}$ and $J_{o}^{*}$ favoring a reduction in the hiring rates of both segments.

(ii) The fall in the hiring rate of young workers is steeper since these workers have a longer horizon.

(iii) Both the scrapping time of the old segment and the scrapping time of the young segment are reduced.

\section{Proof}

Part (i): In none of the segments is the job creation curve affected and the only observed shift corresponds to the job destruction curve which moves downwards:

- In the old segment:

$$
\left.\frac{\partial J_{o}}{\partial g}\right|_{T_{o}=c t e}=(1-\eta) \int_{0}^{T_{o}}\left(-e^{g s} \omega\left(\theta_{o}\right) s\right) e^{-\left(r+\delta+\lambda_{o}\right) s} d s<0
$$

- In the young segment:

$$
\begin{aligned}
\left.\frac{\partial J_{y}}{\partial g}\right|_{T_{y}=c t e} & =(1-\eta) \int_{0}^{T_{y}}\left(-e^{g s} \omega\left(\theta_{y}\right) s\right) e^{-\left(r+\delta+\lambda_{y}\right) s} d s \\
& +\lambda_{y} \int_{0}^{T_{y}} \frac{\partial J_{o}(0, s)}{\partial g} e^{-\left(r+\delta+\lambda_{y}\right) s} d s<0
\end{aligned}
$$

The new equilibrium in each of the segments is characterized by lower values of $J_{i}^{*}$ and $\theta_{i}^{*}$ for $i=y, o$, implying a fall in the hiring rates.

Part (ii) can be deduced from (45) and (46). Indeed, at the limit, we have $\lambda_{y}=\lambda_{o}$ : in this case, $\left.\left|\frac{\partial J_{o}}{\partial g}\right|_{T_{o}=c t e}|<| \frac{\partial J_{y}}{\partial g}\right|_{T_{y}=c t e} \mid$. Because we assume $\lambda_{y}<\lambda_{o}$, we have $\left.\left|\frac{\partial J_{o}}{\partial g}\right|_{T_{o}=c t e}|<| \frac{\partial J_{y}}{\partial g}\right|_{T_{y}=c t e} \mid$.

We start the proof of part (iii) with the analysis of the old segment. The equilibrium asset value of a job occupied by an old worker is given by:

$$
J_{o}^{*}=(1-\eta) x \int_{0}^{T_{o}^{*}}\left(1-e^{g\left(s-T_{o}^{*}\right)}\right) e^{-\left(r+\delta+\lambda_{o}\right) s} d s
$$

It is easy to show that the right hand side of the previous equation is increasing in $g$ and $T_{o}^{*}$. At the same time, we have just found that the job destruction curve of the old segment shifts down when $g$ increases, leading to a reduction in the equilibrium value $J_{o}^{*}$ (since the job creation curve is not affected by $g$ ). Because an increase in the growth rate fosters a reduction in $J_{o}^{*}$, and because we know that the right hand side of (43) is increasing in $g$ and $T_{o}^{*}$, then $T_{o}^{*}$ must 
necessarily decrease in order to induce the reduction in the equilibrium value $J_{o}^{*}$. Therefore $\frac{\partial T_{o}^{*}}{\partial g}<0$.

Concerning the young segment, the equilibrium asset value of a job is given by:

$$
J_{y}^{*}=(1-\eta) x \int_{0}^{T_{y}^{*}}\left(1-e^{g\left(s-T_{y}^{*}\right)}\right) e^{-\left(r+\delta+\lambda_{y}\right) s} d s+\lambda_{y} \int_{0}^{T_{y}^{*}}\left[J_{o}(0, s)-e^{g\left(s-T_{y}^{*}\right)} J_{o}\left(0, T_{y}^{*}\right)\right] e^{-\left(r+\delta+\lambda_{y}\right) s} d s
$$

As previously, we can show that the right hand side of the equation is increasing ${ }^{20}$ in $\mathrm{g}$ and $T_{y}^{*}$. Because the job destruction curve of the young segment shifts down when $g$ increases, leading to a reduction in the equilibrium value $J_{y}^{*}$, and because we know that the right hand side of (44) is increasing in $g$ and $T_{y}^{*}$, then $T_{y}^{*}$ must necessarily decrease in order to induce the reduction in the equilibrium value $J_{y}^{*}$. Therefore $\frac{\partial T_{y}^{*}}{\partial g}<0$.

\subsection{The equilibrium situation when the possibility of updating a technology is available}

The values of a job filled in the old and the young segments when renovation is possible are respectively given by:

$$
\begin{aligned}
J_{o}= & \max _{T_{o}^{R}}\left\{(1-\eta) \int_{0}^{T_{o}^{R}}\left[x-e^{g s} \omega\left(\theta_{o}\right)\right] e^{-\left(r+\delta+\lambda_{o}\right) s} d s+e^{-\left(r+\delta+\lambda_{o}-g\right) T_{o}^{R}}\left[J_{o}-I\right]\right\} \\
J_{y}= & \max _{T_{y}^{R}}\left\{(1-\eta) \int_{0}^{T_{y}^{R}}\left[x-e^{g s} \omega\left(\theta_{y}\right)\right] e^{-\left(r+\delta+\lambda_{y}\right) s} d s+e^{\left(r+\delta+\lambda_{y}-g\right) T_{y}^{R}}\left[J_{y}-I\right]\right. \\
& \left.+\lambda_{y} \int_{0}^{T_{y}^{R}} J_{o}(0, s) e^{-\left(r+\delta+\lambda_{y}\right) s} d s\right\}
\end{aligned}
$$

$$
\begin{aligned}
&{ }^{20} \text { Because } s<T_{y}^{*} \text { we find: } \\
& \begin{aligned}
\frac{\partial J_{y}^{*}}{\partial T_{y}^{*}} & =(1-\eta) x \int_{0}^{T_{y}^{*}}\left[g e^{g\left(s-T_{y}^{*}\right)}\right] e^{-\left(r+\delta+\lambda_{y}\right) s} d s \\
& +\lambda_{y} \int_{0}^{T_{y}^{*}}\left[g e^{g\left(s-T_{y}^{*}\right)} J_{o}\left(0, T_{y}^{*}\right)-e^{g\left(s-T_{y}^{*}\right)} \frac{\partial J_{o}\left(0, T_{y}^{*}\right)}{\partial T_{y}^{*}}\right] e^{-\left(r+\delta+\lambda_{y}\right) s} d s>0 \\
\frac{\partial J_{y}^{*}}{\partial g} & =(1-\eta) x \int_{0}^{T_{y}^{*}}\left[-\left(s-T_{y}^{*}\right) e^{g\left(s-T_{y}^{*}\right)}\right] e^{-\left(r+\delta+\lambda_{y}\right) s} d s \\
& +\lambda_{y} \int_{0}^{T_{y}^{*}}\left[\frac{\partial J_{o}(0, s)}{\partial g}-\left(s-T_{y}^{*}\right) e^{g\left(s-T_{y}^{*}\right)} J_{o}\left(0, T_{y}^{*}\right)\right. \\
& \left.-e^{g\left(s-T_{y}^{*}\right)} \frac{\partial J_{o}\left(0, T_{y}^{*}\right)}{\partial g}\right] e^{-\left(r+\delta+\lambda_{y}\right) s} d s
\end{aligned}
\end{aligned}
$$

For reasonable parameter values we can prove that $\frac{\partial J_{y}^{*}}{\partial g}>0$ 
with $J_{i}(t, t)=p(t) J_{i}$, when $\tau=t=0$, for $i=y, o$. The optimal choices of the renovation horizon are obtained solving the right hand side problem of equations (47) and (48):

$$
\begin{aligned}
& \omega\left(\theta_{o}\right)=\frac{x}{e^{g T_{o}^{R}}}-\frac{J_{o}-I}{(1-\eta)}\left(r+\delta+\lambda_{o}-g\right) \\
& \omega\left(\theta_{y}\right)=\frac{x}{e^{g T_{y}^{R}}}-\frac{\left(r+\delta+\lambda_{y}-g\right)}{1-\eta}\left(J_{y}-I\right)+\frac{\lambda_{y}}{e^{g T_{y}^{R}}(1-\eta)} J_{o}\left(0, T_{y}^{R}\right)
\end{aligned}
$$

Replacing in equations (47) and (48) yields:

$$
\begin{aligned}
I= & (1-\eta) x \int_{0}^{T_{o}^{R}}\left[1-e^{g\left(s-T_{o}^{R}\right)}\right] e^{-\left(r+\delta+\lambda_{o}\right) s} d s \\
I= & (1-\eta) x \int_{0}^{T_{y}^{R}}\left[1-e^{g\left(s-T_{y}^{R}\right)}\right] e^{-\left(r+\delta+\lambda_{y}\right) s} d s \\
& +\lambda_{y} \int_{0}^{T_{y}^{R}}\left[J_{o}(0, s)-e^{g\left(s-T_{y}^{R}\right)} J_{o}\left(0, T_{y}^{R}\right)\right] e^{-\left(r+\delta+\lambda_{y}\right) s} d s
\end{aligned}
$$

for the old workers and for the young workers.

Property 3b The renovation horizon for old workers $\left(T_{o}^{R}\right)$ increases with the updating cost and the probability of retirement, whereas it decreases in the case of an acceleration in the pace of growth ${ }^{21}$.

Proof See equation (51).

A low retirement age discriminates against old workers, since updating will become less probable for two reasons. First, the expected value of a job filled by an old worker $\left(J_{o}^{*}\right)$ falls, making less likely the probability to update (the inequality $I<J_{o}^{*}$ is less likely to hold). Secondly, in spite of the rise in the scrapping time associated with old positions fostered by the rise in $\lambda_{o}$, the optimal renovation horizon increases too. As a result we may find $T_{o}^{R} \lesseqgtr T_{o}^{*}$.

An acceleration in the rate of technological progress reduces the optimal renovation horizon as well as the optimal scrapping time. Simultaneously, the expected value of the job falls, so that we are less likely to find $I<J_{o}^{*}$. Renovation becomes therefore less probable.

\section{Appendix. Match heterogeneity and aging: why are some old workers are retrained?}

Evidently, it seems counterintuitive to claim that no one in the old segment benefits from technological updating. Furthermore, working with the French Complementary Survey on Training,

\footnotetext{
${ }^{21}$ For young workers, for reasonable parameter values, the implementation horizon increases with the implementation cost and decreases with the growth rate and the probability of retirement.
} 
we find that around $44 \%$ of managers ( $38 \%$ of technicians) between 51 and 55 years old and $34 \%$ of those (21\% of technicians) between 56 and 60 years old receive training paid for by the firm in the case of technological change. Why do firms train some old workers if their working horizon is short? Under which conditions does this capitalization effect (renovation of an already existing technology) overcome the creative destruction effect (destruction of an already existing old job) in the older workers' case? This Appendix aims to provide an answer to these questions.

We now introduce in the model a random idiosyncratic component $\epsilon$ in the productivity which becomes $x \epsilon . \epsilon$ is distributed according to a cumulative function $F(\epsilon)$ and its value is revealed once the worker and the firm meet.

Without a renovation opportunity and in the presence of rigid wages, the destruction age of a job equals $T^{*}(\epsilon)=\frac{\ln (x \epsilon)-\ln b}{g}$, for a given match-specific productivity $\epsilon^{22}$. Note that $T^{*}(\epsilon) \geq 0$ for $\epsilon \geq \frac{b}{x} 23$. Finally, these equations show that $\partial T^{*}(\epsilon) / \partial \epsilon>0$ implying that firms keep high productivity workers for a longer period of time. Moreover, property $3 \mathrm{a}\left(\partial T^{*}(\epsilon) / \partial g<0\right)$ and property 1a $\left(\partial T^{*}(\epsilon) / \partial \lambda_{o}=0\right)$ still hold.

Implementing a new technology is the best option only if this horizon is lower than the scrapping time, $T_{o}^{R *}(\epsilon)<T^{*}(\epsilon)$. If firms have the opportunity of renovating, the updating horizon for old workers ${ }^{24}$, denoted $T_{o}^{R *}(\epsilon)$, solves

$$
I=x \epsilon(1-\eta) \int_{0}^{T_{o}^{R *}(\epsilon)}\left[1-e^{g\left(s-T_{o}^{R *}\right)}\right] e^{-\left(r+\delta+\lambda_{o}\right) s} d s
$$

We conclude that $\partial T_{o}^{R *}(\epsilon) / \partial I>0, \partial T_{o}^{R *}(\epsilon) / \partial \lambda_{o}>0$ and $\partial T_{o}^{R *}(\epsilon) / \partial \epsilon<0$, implying that the technology is updated more frequently in a good match (furthermore, the equilibrium value $J_{o}^{*}$ increases with the productivity level). Indeed a good match is a scarce resource that the firm tries to preserve: renovation insures that the quality of the match is maintained. Conversely, for every new match the firm must draw a new match-specific productivity. This last option, implying lay offs, is preferred by the firm when its actual $\epsilon$ is $l_{0}{ }^{25}$.

\footnotetext{
${ }^{22}$ If wages are flexible the scrapping time is given by $T^{*}(\epsilon)=\frac{\ln (x \epsilon)-\ln \omega\left(\theta_{o}\right)}{g}$

${ }^{23} \epsilon \geq \frac{\omega\left(\theta_{o}\right)}{x}$ for flexible wages

${ }^{24}$ The implementation horizon for young workers, $T_{y}^{R *}(\epsilon)$, is given by:

$$
\begin{aligned}
I= & x \epsilon(1-\eta) \int_{0}^{T_{y}^{R *}(\epsilon)}\left[1-e^{g\left(s-T_{y}^{R *}\right)}\right] e^{-\left(r+\delta+\lambda_{y}\right) s} d s \\
& +\lambda_{y} \int_{0}^{T_{y}^{R *}(\epsilon)}\left[J_{o}^{R}(0, s)-e^{g\left(s-T_{y}^{R *}\right)} J_{o}^{R}\left(0, T_{y}^{R *}\right)\right] e^{-\left(r+\delta+\lambda_{y}\right) s} d s
\end{aligned}
$$
}

\footnotetext{
${ }^{25}$ These results are robust to the introduction of a flexible wage.
} 
Firms renovate only positions having a match-specific productivity greater than a critical value $R_{i}$ solving ${ }^{26}$ :

$$
T_{o}^{R *}\left(R_{o}\right)=T^{*}\left(R_{o}\right) \Leftrightarrow J_{o}\left(R_{o}\right)=J_{o}^{R}\left(R_{o}\right)
$$

Jobs having a productivity level above $R_{o}$ constitute the set of renovated matches. Because $\partial T_{o}^{R *}(\epsilon) / \partial I>0$ we have $\partial R_{o} / \partial I>0$, a rise in the renovation cost is necessarily associated with an increase in the reservation productivity $R_{o}$ so as to keep $T_{o}^{R *}\left(R_{o}\right)=T_{o}^{*}\left(R_{o}\right)$. The set of renovated jobs then decreases. This result remains robust when assuming flexible wages.

When $g$ accelerates there is a reduction in both the renovation horizon and the scrapping time. Independently of the wage determination process, we can distinguish among three possible situations. For realistic parameter values, our numerical simulations show ${ }^{27}$ that the reduction in the renovation horizon fostered by the rise in $g$ is greater than that of the scrapping time. Consequently, the reservation productivity $R_{o}$ increases in order to reestablish the equality $T_{o}^{R *}\left(R_{o}\right)=T^{*}\left(R_{o}\right)$. The set of renovated jobs will then fall. The second possible but less likely situation, corresponds to the case where the reduction, the renovation and the scrapping horizon is such that the equality $T_{o}^{R *}\left(R_{o}\right)=T^{*}\left(R_{o}\right)$ directly holds. $R_{o}$ thus remains unchanged and the set of renovated jobs does not vary either. Thirdly, if the acceleration in the pace of technological progress yields a greater reduction of the scrapping time, the reservation productivity $R_{o}$ decreases, fostering a rise in the set of renovated jobs.

\section{References}

Abowd, J., J. Haltiwanger, J. Lane, K. McKinney, and K. Sandusky. 2007. "Technology and the Demand for Skill: an Analysis of Within and Between Firm Differences." NBER Working Paper 13043.

Aghion, P., and P. Howitt. 1994. "Growth and Unemployment." Review of Economic Studies 61 (3): 477-496.

\footnotetext{
${ }^{26}$ For young workers:$$
T_{y}^{R *}\left(R_{y}\right)=T^{*}\left(R_{y}\right) \Leftrightarrow J_{y}\left(R_{y}\right)=J_{y}^{R}\left(R_{y}\right)
$$

${ }^{27}$ Available from the authors upon request.
} 
Ahituv, A., and J. Zeira. 2000. "Technical Progress and Early Retirement." CEPR Dicussion Paper, no. 2614.

Aubert, P., E. Caroli, and M. Roger. 2006. "New Technologies, Workplace Organization and the Age Structure of the Workforce: firm-level evidence." Economic Journal 116 (February): 73-93.

Bartel, A., and N. Sichermann. 1993. "Technological Change and Retirement Decisions of Older Workers." Journal of Labor Economics 11 (1): 162-182.

Bassanini, A., and R. Duval. 2006. "Employment patterns in OECD countries: reassessing the role of policies and institutions." Social, employment and migration Working Papers, no. 35 .

Behaghel, L., and N. Greenan. 2007. "Training and Age-Biased Technical Change." LEA Working Paper, no. 0705.

Berman, E., J. Bound, and Z. Griliches. 1994. "Changes in the demand for skilled labor within U.S. manufacturing: evidence from the Annual Survey of Manufacturers." Quarterly Journal of Economics 109:367-397.

Blanchard, O., and J. Wolfers. 2000. "The Role of Shocks and Institutions in the Rise of European Unemployment: The Aggregate Evidence." The Economic Journal 110 (462): 1-33 (March).

Borghans, L., and B. Weel. 2002. "Do Older Workers Have More Trouble Using a Computer Than Younger Workers." Research in Labour Economics 21:139-173.

Castaneda, A., J. Diaz-Gimenez, and V. Rios-Rull. 2003. "Accounting for earnings and wealth inequality." Journal of Political Economy 111 (4): 818-857.

Cheron, A., J-O. Hairault, and F. Langot. 2007. "Job Creation and Job Destruction over the Life Cycle: The Older Workers in the Spotlight." IZA Discussion Paper, no. 2597.

Costain, J., and M. Reiter. 2008. "Business Cycles, Unemployment Insurance, and the Calibration of Matching Models." Journal of Economic Dynamics and Control, forthcoming $32: 1120-1155$.

Davis, S., J. Haltiwanger, and S. Schuh. 1996. Chapter 2 of Job Creation and Destruction. Massachusetts Institute of Technology. 
Gomez-Salvador, R., J. Messina, and G. Vallanti. 2004. "Gross job flows and institutions in Europe." Labour Economics 11 (4): 469-485 (August).

Gruber, G., and D. Wise. 1999. Social Security and Retirement around the World. The Chicago University Press.

Hagedorn, M., and I. Manovskii. 2008. "The Cyclical Behaviour of Equilibrium Unemployment and Vacancies revisited." American Economic Review, forthcoming.

Hairault, J.O., F. Langot, and T. Sopraseuth. 2008. Distance to retirement and older workers employment: the case for delaying the retirement age. mimeo.

Hall, R. 2005. "Employment Fluctuations with Equilibrium Wage Stickiness." American Economic Review 95 (1): 50-65 (March).

Hall, R., and P. Milgrom. 2008. "The Limited Influence of Unemployment on the Wage Bargain." American Economic Review 98 (4): 1653-1674 (September).

Ljunqvist, J., and T. Sargent. 2008. "Two questions about European Unemployment." Econometrica $76: 1-29$.

Machin, S., and J. Van Reenen. 1998. "Technology and changes in skill structure: Evidence from seven OECD countries." Quarterly Journal of Economics 113:1215-44.

Moreno-Galbis, E., and H. Sneessens. 2007. "Unemployment, capital-skill complementarity and embodied technological progress." Louvain Economic Review 73:241-272.

Mortensen, D., and E. Nagypal. 2007. "More on Unemployment and Vacancy Fluctuations." Review of Economic Dynamics 10 (3): 327-347.

Mortensen, D., and C. Pissarides. 1998. "Technological Progress, Job Creation and Job Destruction." Review of Economic Dynamics 1:733-753.

Nagypal, E. 2007. "Labor Market Fluctuations, On-the-Job Search and the Acceptance Curse." Mimeo.

Petrongolo, B., and C. Pissarides. 2001. "Looking Back into the Black Box: a Survey of the Matching Function." Journal of Economic Literature 39:390-431.

Pissarides, C. 1990. Equilibrium Unemployment Theory. Edited by MIT Press. Cambridge, Massachusetts: MIT Press.

—. 2007. "The Unemployment Volatility Puzzle: Is Wage Stickiness the Answer?" Mimeo. 
Pissarides, C., and G. Vallanti. 2007. "The impact of TFP growth on steady-state unemployment." International Economic Review 48 (May): 607-640.

Shimer, R. 2005. "The Dyclical Behavior of Equilibrium Unemployment and Vacancies." American Economic Review 95 (1): 25-49 (March).

Tripier, F. 2007. "The long run relationship between growth and unemployment. A transatlantic perspective." Mimeo. 